\title{
Pharmaciana
}

Vol.11, No.3, Nov 2021, Page. 394-405

ISSN: 2088 4559; e-ISSN: 24770256

\section{The effect of spray-drying temperature on Centella asiatica extract- $\beta$ cyclodextrin-maltodextrin nanoparticle characteristics and stability}

\author{
Aditya Trias Pradana ${ }^{* 1,2}$, Roisah Nawatila ${ }^{1}$, Fawandi Fuad Alkindi ${ }^{3}$, \\ Ni Putu Resa Darmayani ${ }^{4}$, Eka Desi Susanti ${ }^{4}$ \\ ${ }^{I}$ Department of Pharmaceutics, Faculty of Pharmacy, University of Surabaya, \\ Raya Kalirungkut Street, Surabaya, East Java, Indonesia \\ ${ }^{2}$ Department of Pharmaceutics and Industrial Pharmacy, Faculty of Pharmaceutical Sciences, Chulalongkorn \\ University, Bangkok, Thailand \\ ${ }^{3}$ Department of Pharmaceutical Chemistry, Faculty of Pharmacy, University of Surabaya, \\ Raya Kalirungkut Street, Surabaya, East Java, Indonesia \\ ${ }^{4}$ Faculty of Pharmacy, University of Surabaya, \\ Raya Kalirungkut Street, Surabaya, East Java, Indonesia
}

\begin{abstract}
Centella asiatica extract has low solubility in water. Material modification needs to be conducted to increase the dissolution rate of Centella asiatica extract. The particle size reduction to nano-size was carried out to increase surface contact with aqueous media. High surface contact was expected to increase the solubility and absorption rate. Nanoparticles were prepared with $34 \%$ maltodextrin and $6 \%$ $\beta$-cyclodextrin as a stabilizer and dried by a spray-drying method. High temperature in the spray drying process can affect the physical and chemical characteristics of the nanoparticles, so the inlet temperature in this study was observed as parameter variations, on $140^{\circ} \mathrm{C}, 150^{\circ} \mathrm{C}$, and $160^{\circ} \mathrm{C}$. The formed nanoparticles then being tested on several parameters, including physical appearance, moisture content, particle size, shape, and morphology. The chemical stability of the active ingredients during the drying process was assessed from the $\mathrm{pH}$ value changes and the content of quercetin as an antioxidant post drying process, compared to the initial content. The test results show that the nanoparticles have been formed. The inlet temperature of $160^{\circ} \mathrm{C}$ produced the most physically optimum spherical nanoparticles, with a particle size of $191.533 \pm 18.791 \mathrm{~nm}$ and relatively homogeneous with a polydispersity index (PDI) value of $0.113 \pm 0.057$. However, temperatures that are too high indicate poor chemical stability. The poor chemical stability can be seen from the quercetin content that decreased significantly after the drying process, until the remaining $53.87 \pm 0.55 \%$ and $49.52 \pm 0.97 \%$ for temperatures of $140^{\circ} \mathrm{C}$ and $160^{\circ} \mathrm{C}$, respectively. These results indicate that the combination of $\beta$-cyclodextrin and maltodextrin can not encapsulate and maintain the stability of the active ingredients during the spray drying process. A significant reduction of inlet temperature is needed to get dry nanoparticles with the most optimum physical mixture and chemical stability.
\end{abstract}

Keywords: nanoparticle, Centella asiatica, quercetin, $\beta$-cyclodextrin, maltodextrin, spray-drying

\section{*Corresponding author:}

Aditya Trias Pradana

Department of Pharmaceutics, Faculty of Pharmacy, University of Surabaya,

Raya Kalirungkut Street, Surabaya, East Java, Indonesia,

Email: aditya_trias@staff.ubaya.ac.id 


\section{INTRODUCTION}

Centella asiatica is a cosmopolite plant with a wide distribution area, especially in the tropics and subtropics (Winarto and Surbakti, 2003). The plant comes from Asia and grows in various countries such as the Philippines, China, India, Sri Lanka, Madagascar, Africa, and Indonesia. The chemical content of Centella asiatica has an important role in medicine and nutraceuticals (Kumar and Gupta, 2003). The highest bioactive compounds in Centella Asiatica were asiaticoside, madecassoside, asiatic, and madecassic acid from the triterpene class that has been well-known. The compounds include brahmoside, centelloside, glycosides, and alkaloids. Meanwhile, well-known flavonoid compounds such as kaempferol, quercetin, rutin, catechin, naringin, and apigenin contributed to the total phenolic of Centella Asiatica. (Idris and Nadzir, 2021)

Small amounts of luteolin, apigenin, and kaempferol were seldom present in some parts of Centella asiatica. It was known previously that each $100 \mathrm{~g}$ dry weight of Centella asiatica leaf extract contained a total flavonoid equivalent to quercetin of $1.19 \pm 0.01$. Flavonoids contribute to the activity of Centella asiatica on in-vitro Angiotensin-Converting Enzyme (ACE) inhibitors and antihypertension in rats, calculated by systolic blood pressure (SBP), diastolic blood pressure (DBP), mean arterial pressure (MAP), and heart rate (HR) (Nansy et al., 2015).

However, the very high benefits of its extract are constrained by its low water solubility. The problem can also be seen from the extraction process using $70 \%$ ethanol which is more optimal than extraction using water (Pramono and Ajiastuti, 2004). The low solubility of Centella asiatica extracts in water affecting its dissolution step and the absorption rate in the medium at the site of absorption (Sulaiman, 2007). The dissolution of the drug substance into the aqueous medium will also be a determining step for drug bioavailability (Shargel and Yu, 2016). Since the solubility of Centella asiatica extract was poor, it can cause slow absorption in the body, and the effect of the drug will become low.

One of the approaches to increase drug dissolution rate was done by reducing particle size, decreasing crystallinity, and increasing surface area. Several studies have been conducted to increase the drug dissolution rate by reducing the particle size, micro, and nanoparticle sizes. In addition, the solid dispersion method is used by dispersing the drug in a hydrophilic matrix. When the solid dispersion is in contact with aqueous media, the carrier will quickly dissolve. As a result, the drug will be released as particles. The reaction results in the surface area of the drug particles increases, causing the dissolution rate and drug bioavailability to increase. (Dixit et al., 2012).

The spray drying method was the process used to form nanoparticles to increase the solubility and dissolution rate of the drug. This method uses high pressure and a hydrophilic polymer as the matrix. The results obtained are a dry powder containing nanocrystals coated with the hydrophilic carrier (Bansal et al., 2012). The quality and efficiency of the spray drying process depend on several parameters. It includes droplet size distribution, airflow pattern in the air chamber, inlet temperature, feed flow rate, and drying air flow rate (Nielsen, 2010). The advantage of using a spray dryer is a product that results in uniform particle size and spherical shape. In addition, this process also has a relatively short drying time compared to other drying methods. In addition, we can use this method on thermolabile materials. According to research conducted by (Dewi and Satibi, 2015), the researcher can get the best drying time when drying temperature of $140^{\circ} \mathrm{C}$ and $150^{\circ} \mathrm{C}$, the higher the drying air temperature will accelerate the uptake of vapor from the material so that the drying process becomes faster. In addition, the substance also became drier and did not stick much to the walls of the drying chamber, easily separated, entered the cyclone, and produced a better powder.

In the manufacture of nanocrystals, the addition of a stabilizer is needed to prevent agglomeration caused by too small particle size. It can cause the particles to stick to each other and increase the particle size (Kumar, 2014). One of the stabilizers commonly used in the manufacture of nanocrystals by the spray drying method is maltodextrin. Maltodextrin has many applications; one of them is as a thickening agent. It can be used as an emulsifier and filler (Kembaren et al., 2014). In addition, according to research conducted by Watson et al., the combination of maltodextrin with $\beta$ cyclodextrin can simultaneously increase the stability of the active ingredient. The cavity in the 
cyclodextrin is composed of hydrophobic glucose residues, while the outside is hydrophilic due to the presence of hydroxyl groups. In solution, the water molecules in the cyclodextrin cavity are replaced by non-polar molecules or non-polar parts of the guest molecules (drugs) and move back and forth towards the host-guest inclusion complex. The drug molecules in the complex form will quickly be in equilibrium with the free molecules in the solution (Loftsson et al., 2005). Compared to the free molecular form, the guest molecule (drug) complexed with cyclodextrin has new physicochemical properties. One of them is increased solubility in water.

In this study, the researcher made the observations on the inlet temperatures effect of $140^{\circ} \mathrm{C}$, $150^{\circ} \mathrm{C}$, and $160^{\circ} \mathrm{C}$ in the spray drying process on the characteristics of the obtained Centella asiatica- $\beta$ cyclodextrin-maltodextrin nanoparticles, including physical characteristics, particle size, shape, morphology, moisture content, and qualitative densitometric tests. To ensure that the chemical stability of the active ingredients is maintained during the spray drying process, testing also needs to be carried out. The $\mathrm{pH}$ of nanoparticles and quercetin content of nanoparticles were determined based on pHmeter determination and the validated assay method with High Performance Liquid Chromatography (HPLC). Quercetin was used based on the target of activity as an anti-hypertensive agent, and thus substance was well known as a kind of flavonoid with purposed activity. The results of the tests will later become the basis for ensuring that the spray drying process with the selected inlet temperature can produce nanoparticles with good physical and chemical characteristics.

\section{MATERIALS AND METHOD Materials}

The raw materials used in the research include Centella asiatica simplicia was purchased from Materia Medika Malang, Indonesia, Quercetin (Sigma Aldrich, USA), Saponin - CAS 8047-15-2 (Calbiochem, Merck, Germany), $\beta$-cyclodextrin pharmaceutical grade (Sigma Aldrich, USA), Maltodextrin DE 10-12 pharmaceutical grade merk (Zhucheng Dhongxiao, China), Acetic acid glacial (Merck, Germany), Acetonitrile HPLC grade (Merck, Germany), Methanol HPLC grade (Merck, Germany), water for injection (PT Ikapharmindo Putramas, Indonesia) and deionized water.

While the instruments needed in the preparation and evaluation were in the form of Spray Dryer (BÜCHI Mini Spray Dryer B-290, Germany), Analytical Balance (Mettler Toledo, Germany), Ultra turra disperser (IKA T-25, China), Vortex Mixer (Vortex MaxiMix II, Thermo Scientific, Germany), 1 set of High-Performance Liquid Chromatography (Waters 2489, Water Corporation, USA): HPLC

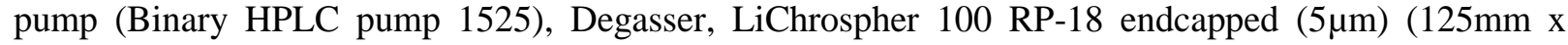
4mm) (Merck, Germany), pH meter (Crison GLP 21, Crison Instrument, S.A., Spain), Moisture content balance (Ohaus MB45, USA), Densitometer (Camag, Swiss), Scanning Electron Microscopy (SEM) (Jeol, Japan), and Particle Size Analyzer (PSA) (Microtrac, USA).

\section{Methods}

\section{Centella asiatica extract preparation}

A 500 milligrams of Centella asiatica simplicia was put into an electric stirring macerator. It stirred for 30 minutes in $2.5 \mathrm{~L}$ ethanol $70 \%$ and macerated for 24 hours. After being filtered, the filtrate obtained was evaporated in the evaporator until a flowing viscous compound was formed (water content of $5-30 \%$ ) with a yield of maceration $>10 \%$. Evaporation is then continued in a porcelain cup over a water bath until a thick extract is obtained for three hours total time at $55^{\circ} \mathrm{C}$.

\section{Centella asiatica nanoparticle formulation}

The composition used in the preparation of Centella Asiatica nanoparticles is shown in Table 1. Centella Asiatica extract was weighed as much as 4 grams and dissolved in $50 \mathrm{ml}$ of ethanol. On the other hand, the researcher dissolved $\beta$-cyclodextrin and maltodextrin in deionized water. The stabilizer solution is mixed with the extract solution at $5,000 \mathrm{rpm}$ for $5 \mathrm{~min}$ until homogeneous. Furthermore, the mixture was dried using a spray dryer with inlet temperature variations of $140^{\circ} \mathrm{C}$, 
$150^{\circ} \mathrm{C}$, and $160^{\circ} \mathrm{C}$. The researcher set the aspirator rate and airflow of the machine at $90 \%$ and $40 \%$, respectively. The flowing rate of the solution mixture was $5.5 \mathrm{~mL} / \mathrm{min}$. The nanoparticle of Centella Asiatica extract was formed and surrounded by the hydrophilic matrix as a stabilizer of the spray drying process. However, considering that both phases were in dissolved form (with small dispersion), there might have been a hydrophilic part of the polymer inside the core of nanoparticles. The researcher replicated the formulation process three times and then evaluated the results.

Table 1. Centella asiatica nanoparticle composition

\begin{tabular}{ccc}
\hline Substance & Value & Role \\
\hline Centella asiatica extract & $4 \mathrm{~g}$ & Active pharmaceutical ingredient \\
Maltodextrin & $68 \mathrm{~g}$ & Stabilizer \\
B-cyclodextrin & $12 \mathrm{~g}$ & Stabilizer \\
Ethanol & $50 \mathrm{~mL}$ & Solvent \\
Deionized water & $200 \mathrm{~mL}$ & Solvent \\
\hline
\end{tabular}

\section{Moisture content}

The research did the nanoparticle moisture content test using a moisture content balance $0.5 \mathrm{gram}$ sample was placed in the pan and continued with the drying process by a heating halogen lamp at $100^{\circ} \mathrm{C}$. The heating process was stopped when the desired constant weight of the substance reached. The moisture content was obtained in the display due to comparing the weight difference in the pan before and after the drying process.

\section{Particle size and polydispersity index}

A particle size analyzer was used to determine the particle size, and polydispersity index $50 \mathrm{mg}$ nanoparticle was dispersed in $20 \mathrm{~mL}$ deionized water to avoid multiple scattering effects during analysis. The suspension was then placed into the cuvette, and particle size was observed on the instrument.

\section{Particle shape and morphology}

The interaction between the electron beam and the solid specimen is utilized by a scanning electron microscope (SEM) to produce an image. The three-dimensional appearance of the SEM results is useful for describing the particle shape and surface morphology of the nanoparticles (Ayyad, 2011). Centella asiatica solid simplicia and its nanoparticles were placed on double-sided adhesive carbon tape. Furthermore, the sample was coated with gold for 3 minutes and photographed at the appropriate magnification.

\section{pH of nanoparticle}

The $\mathrm{pH}$ test of nanoparticles was carried out using a $\mathrm{pH}$ meter. The testing process begins with the preparation and cleaning of the electrode. After that, the $\mathrm{pH}$ meter calibration was carried out with three types of standard buffers and continued with physical mixture and nanoparticle sample testing. Nanoparticles made by $140^{\circ} \mathrm{C}$ and $160^{\circ} \mathrm{C}$ inlet temperature were chosen as samples with critical manufacturing variation. The dry sample was prepared as $20 \% \mathrm{w} / \mathrm{v}$ in deionized water before observation.

\section{Qualitative determination of nanoparticle}

Qualitative determination was started by dissolving $50 \mathrm{mg}$ of nanoparticles in $5 \mathrm{~mL}$ of ethanol. 5 $\mu 1$ of the solution and standard were then spotted on the chromatographic system. The area of the saponin spots was measured by densitometry with a UV detector in 254 of wavelength. TLC C18 ODS is used as a fixed phase, while ethyl acetate:toluene: formic acid (60:30:10) is used as a mobile phase. The resulted retention factor (Rf) was compared between the standard and the sample. 


\section{Quercetin content of nanoparticle}

This research measured the chemical stability of the nanoparticles based on the content of quercetin. Quercetin is one of the flavonoid compounds, was chosen to be a marker. The evaluation was carried out using the validated High Performance Liquid Chromatography (HPLC) method. The mobile phase used in the assay is acetonitrile: $2 \%$ acetic acid in water $70: 30(\mathrm{v} / \mathrm{v})$ which flew $1.0 \mathrm{~mL} / \mathrm{min}$. This study used the column of LiChrospher $100 \mathrm{RP}-18(5 \mu \mathrm{m})(125 \mathrm{~mm}$ x $4 \mathrm{~mm})$. The observed sample was injected with a volume of $20.0 \mu 1$, then the quercetin peak was read on a UV detector at $370 \mathrm{~nm}$. All validation parameters, such as linearity, detection limit, quantitative limit, accuracy, precision, and specificity have been carried out and ensured that they meet the requirements before the sample essay. Nanoparticles made at inlet temperatures of $140^{\circ} \mathrm{C}$ and $160^{\circ} \mathrm{C}$ have weighed as much as $100 \mathrm{mg}$ and dissolved in methanol. The two conditions were chosen as critical parameters (lower and higher temperature) to be evaluated. A physical mixture with the same amount of active substance and excipients was used as a comparison. The researcher compared all observations with the concentration of quercetin as standard, which was calculated as $100 \%$ content and repeated three times.

\section{Data Analysis}

The research calculated collected results, and the difference between each group was analyzed by descriptive method and one-way ANOVA. Physical appearances and organoleptic of the nanoparticles were expressed in a descriptive method to show the conformity with the expected specifications. Meanwhile, the significance of the data was analyzed using the one-way ANOVA method to see the effect of differences in inlet temperature on the spray drying process on the characteristics of the nanoparticles formed.

\section{RESULT AND DISCUSSION Physical appearances}

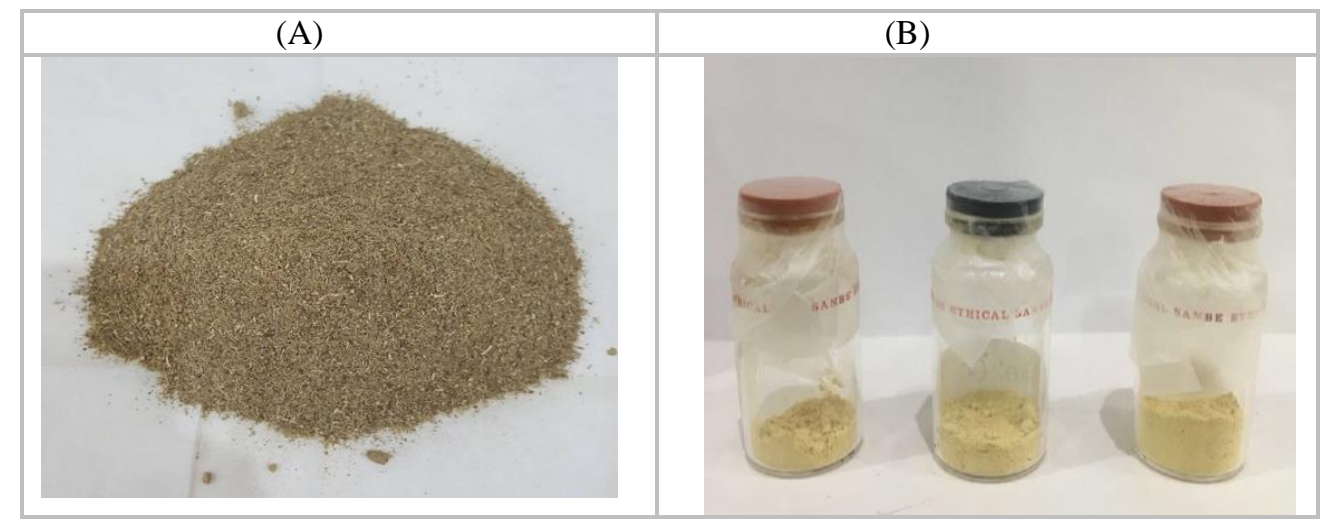

Figure 1. Physical appearances of Centella asiatica (A) Simplicia powder (B) Spray-dried nanoparticle in $140^{\circ} \mathrm{C}, 150^{\circ} \mathrm{C}$, and $160^{\circ} \mathrm{C}$ of inlet temperature, from left to right respectively

The powder observed before treatment had a larger size and was coarse, while after the spray drying process, small and fine powder was obtained, as shown in Figure 1. The added stabilizer made the powder color change from dark green during pretreatment to lighter. The distinctive odor of Centella asiatica was smelled in the nanoparticle products. Visually, it can be seen that the improvement of the physical characteristics of the powder occurred after the spray drying process with three different inlet temperatures. 


\section{Moisture content}

Figure 2 shows the moisture content of nanoparticles formed at three different inlet temperatures, which ranged from $4.43-5.52 \%$. Based on these results, it can be seen that the difference in inlet temperature used in the spray dryer produced nanocrystals with different moisture content. The higher the inlet temperature used, the lower the moisture content in the resulting nanocrystals is. Moisture in the dosage forms will have an impact on microbial growth and its stability during storage (Zambrano et al., 2019). In addition, the physical characteristics of the product, such as compressibility and crushing strength are also affected by the moisture content value (Liu et al., 2020). The decrease in moisture content occurred due to the high inlet temperature. However, the value was still in line with the expectation. The compressibility and crushing strength of the particles will be good enough to be further formulated into other dosage forms, such as tablets. Microbial growth in the product will also be low enough so that the microbiological stability of the product can be maintained, although further testing still needs to be done.

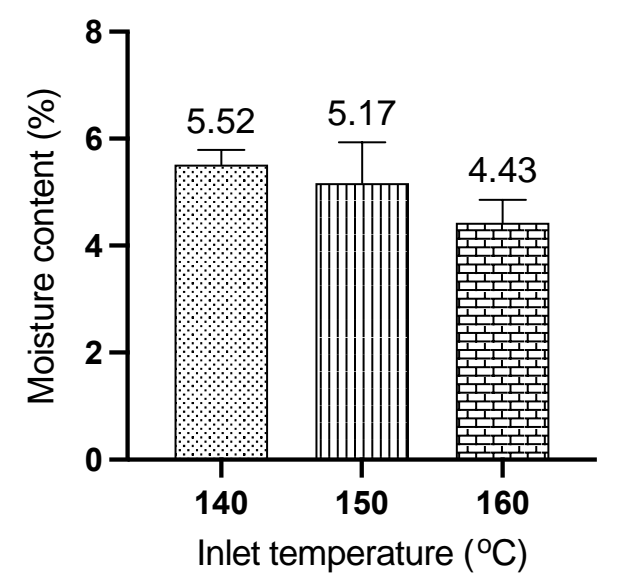

Figure 2. Moisture content average value (number) and deviation (error bar line) of Centella asiatica nanoparticle in different inlet temperature 


\section{Particle size and polydispersity index}

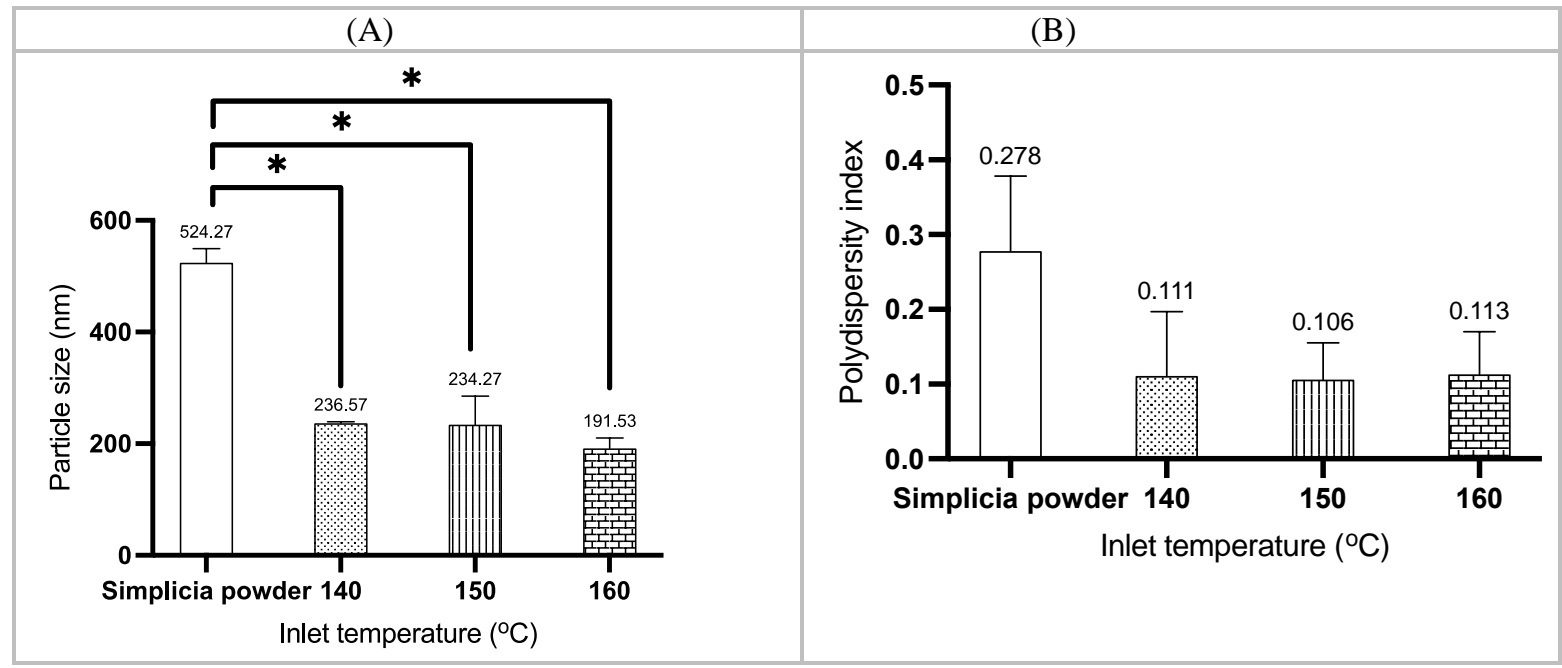

Figure 3. Result of partice size analyzer instrument (A) Particle Size (B) Polydispersity index; number: average particle size and average polydispersity index, error bar: deviation, * means significant different $(\mathbf{p}<0.05)$

Particle size and polydispersity index of Centella asiatica simplicia powder and nanoparticles were obtained with particle size analyzer and shown in Figure 3. Based on the results, it is seen that nanoparticles with smaller sizes have been formed at the three inlet temperatures. The spray drying process with an inlet temperature of $160^{\circ} \mathrm{C}$ resulted in the smallest particle size of $191.533 \pm 18.791$ $\mathrm{nm}$. These results indicate that an increase in the inlet temperature will dry the droplets faster before the formation of agglomerates in the drying chamber. The three drying processes showed statistically different particle sizes $(\mathrm{p}<0.05)$ compared to simplicial powder form. Among the three spray drying process data, there was no significant difference ( $\mathrm{p}>0.05)$.

The polydispersity index (PI) value obtained is also quite good. The low value of the PI approaching zero indicates that the obtained nanoparticles not only have a smaller size but were also relatively uniform in one bulk product. Nanoparticle prepared with $160^{\circ} \mathrm{C}$ inlet temperature was shown higher PI, even the particle size was the smallest. This result shows that the fast-drying process produced non-uniform agglomerates, although the value is insignificant compared to the others ( $>0.05$ ). The success of reducing the particle size into nanoparticles can be a solution to overcome the solubility issue so that the success can increase bioavailability and biological activity (Rachmawati et al., 2016).

\section{Particle Shape and Morphology}

The particle shape and morphology of the powder and nanoparticles are shown in Figure 4. Nanoparticles at the three inlet temperatures seemed to form better particle shape and morphology. The more spherical particle with a smooth surface compared to the raw material powder was resulted from the manufacturing process. Spherical shape and smooth surface benefit its physical stability and prevent agglomeration into a larger structure. In addition, this shape also reduces friction between particles in the later process (Mendes et al., 2021). 


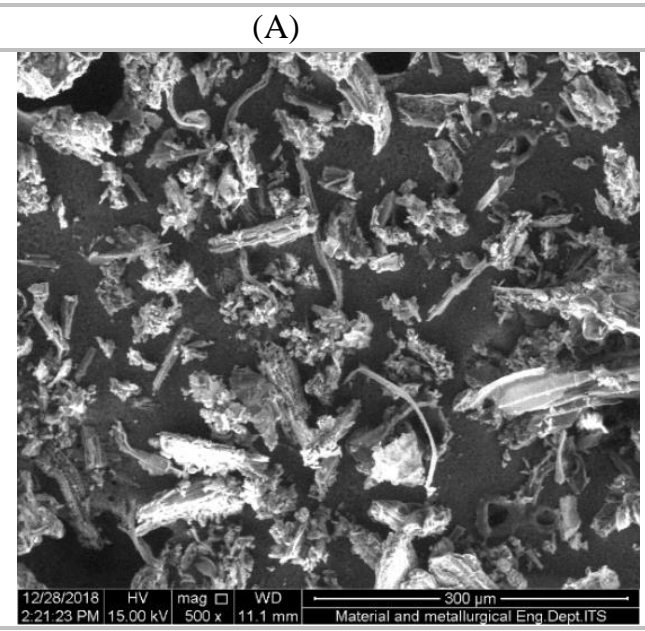

(C)

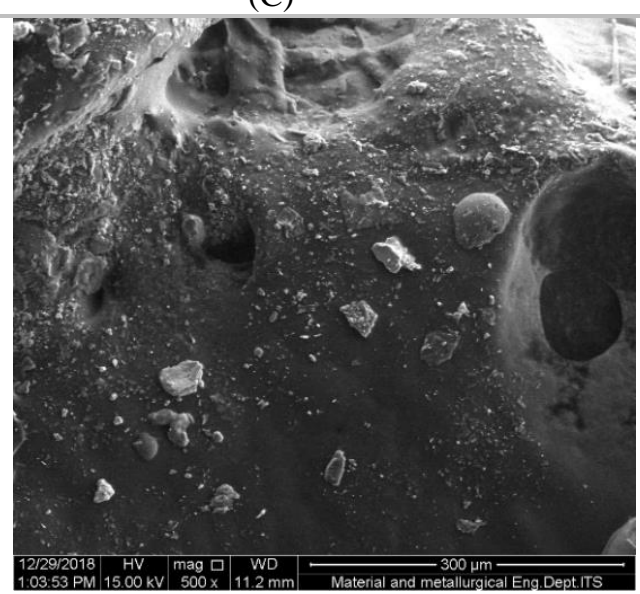

(B)

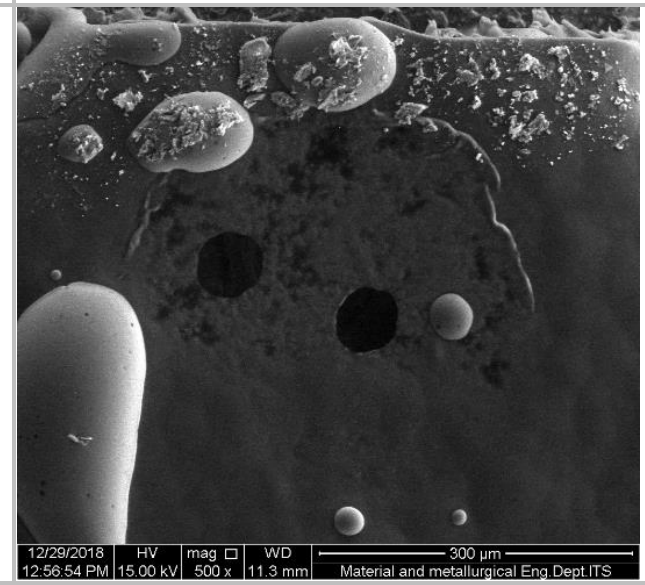

(D)

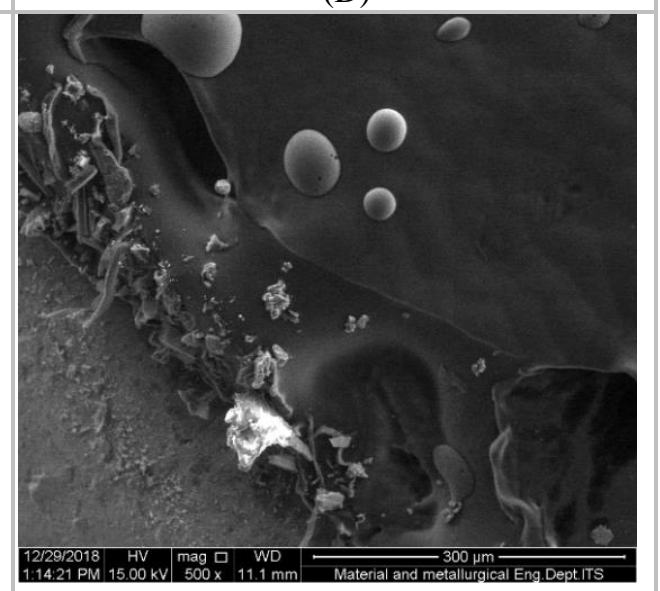

Figure 4. Images of scanning electron microscope with 500x magnification of Centella asiatica simplicia powder (A) and nanoparticles produced by spray drying method in various inlet temperatures, namely at $140^{\circ} \mathrm{C}(\mathrm{B}), 150^{\circ} \mathrm{C}(\mathrm{C})$, and $160^{\circ} \mathrm{C}(\mathrm{D})$

\section{pH of nanoparticle}

The $\mathrm{pH}$ of Centella asiatica physical mixture and nanoparticles as one of the chemical parameters was determined and shown in Figure 5. These results showed a $\mathrm{pH}$ value ranged from $6.04-$ 6.53 , so it was tolerable to be consumed by oral administration. The values of each $\mathrm{pH}$ were not statistically different $(\mathrm{p}>0.05)$, both physical mixture without spray drying process and spray dried substance. The difference indicated that the spray drying process had a significant effect neither on the $\mathrm{pH}$ of the resulting nanoparticles, nor the $\mathrm{pH}$ value changes. 


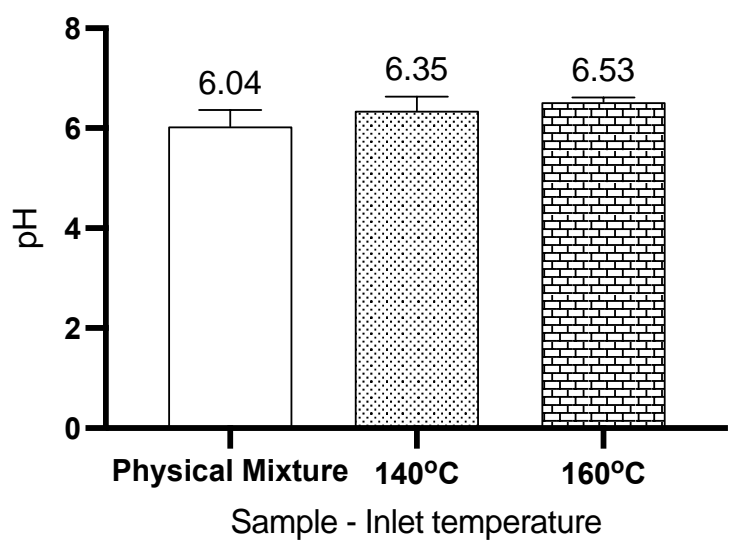

Figure 5. Average pH value (number) and the deviation (error bar line) of physical mixture and nanoparticle in deionized water

\section{Qualitative determination by densitometry}

The sample spots that contained Centella asiatica extract were read on a densitometer with $\lambda \max$ of $301 \mathrm{~nm}$ (Sukmasari and Fatimah, 2006). After the researcher carried out the readings, it was obtained as written in Table 2. Both Rf of standard saponins and Centella asiatica extract were 0.24, which indicated that the thick extraction contained saponins. Rf could not be detected at nanoparticles prepared by 150 and $160^{\circ} \mathrm{C}$. This condition could be due to the saponin content that was very small in both products. The high temperature of the drying process caused instability so that the content of the compound was too low to be observed in the weighted sample.

Table 2. Qualitative result by densitometry

\begin{tabular}{cccc}
\hline Sample & Retention factor & Height & Area \\
\hline Saponin standard & 0.24 & 12.27 & 143.77 \\
Centella asiatica extract & 0.24 & 25.29 & 450.19 \\
Formula 1 $\left(140^{\circ} \mathrm{C}\right)$ & 0.24 & 11.36 & 269.36 \\
Formula 2 $\left(150^{\circ} \mathrm{C}\right)$ & - & - & - \\
Formula 3 $\left(160^{\circ} \mathrm{C}\right)$ & - & - & - \\
\hline
\end{tabular}

\section{Quercetin content of nanoparticle}

Quercetin content assay in physical mixture and nanoparticles began with validation of the analytical method using HPLC. The validation results were shown in Table 3, where the parameters, such as linearity, detection limit, quantitation limit, accuracy, precision, and specificity have met the requirements (United States Pharmaceutical Convention, 2020). Based on these results, the assay method can be used to observe the effect of inlet temperature on the chemical stability of Centella asiatica extraction that is characterized by the quercetin content of the nanoparticles.

Figure 6 shows the quercetin content of the physical mixture and nanoparticles that were spraydried at inlet temperatures of $140^{\circ} \mathrm{C}$ and $160^{\circ} \mathrm{C}$. From the results, it can be seen that grinding and mixing the component into a physical mixture could decrease the quercetin content. It is shown that the stabilizer (a combination of maltodextrin and $\beta$-cyclodextrin) could not maintain the chemical stability of quercetin. An increase in inlet temperature caused a higher degradation of the active ingredient, indicated by a decrease in the quercetin content with a statistically different value $(\mathrm{p}<0.05)$. The reduction of inlet temperature in the spray drying process needs to be carried out while maintaining the optimum physical and chemical characteristics of nanoparticles. This condition considers that the higher inlet temperature $\left(160^{\circ} \mathrm{C}\right)$ is known to produce the best physical characteristics of nanoparticles according to previous tests. 


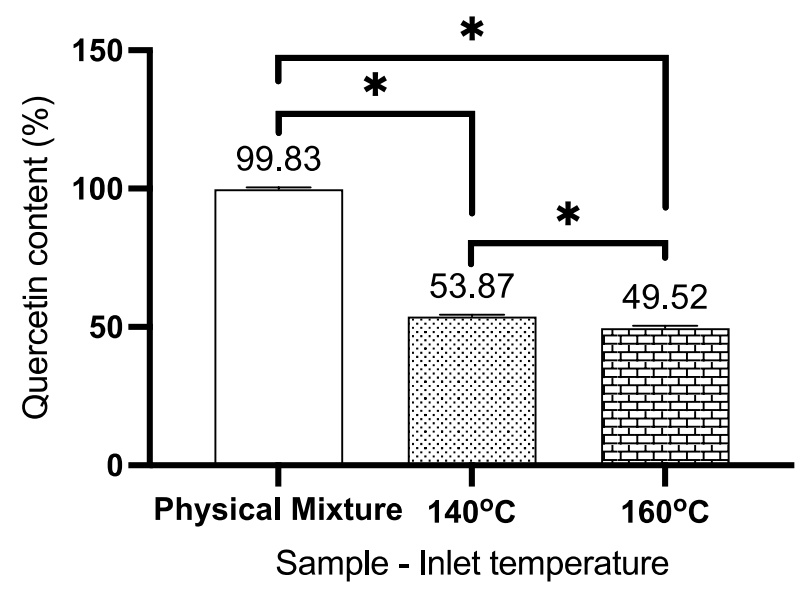

Figure 6. Quercetin content of physical mixture and nanoparticle; number: average quercetin content, error bar: deviation, * means significant different $(\mathbf{p}<0.05)$

Table 3. Validation method of quercetin assay

\begin{tabular}{ccc}
\hline Parameter & Acceptance criteria & Result \\
\hline Linearity & $\mathrm{R}^{2} \geq 0.9$ & $\mathrm{R}^{2}: 0.9986$ \\
Detection limit & & With tailing factor (TF) $\leq 2$ \\
Quantitation limit & & $3.7414 \mathrm{ppm}$ \\
Accuracy & & $12.4714 \mathrm{ppm}$ \\
(Concentration used: $20.16 ;$ & $\%$ Recovery: $80 \%-120 \%$ & $\%$ Recovery: $91.90 \%-119.52 \%$ \\
40.32; 80.64 ppm) & & $\begin{array}{c}\text { Coefficient of variation (CV): } 1.34 \% \\
\text { Precision }\end{array}$ \\
Specificity & Relative standart deviation & Relative standart deviation (RSD): \\
(RSD): $\leq 1 \%$ & $0.013 \%$ \\
(50ppm of quercetin in pure & Relative standart deviation \\
physical mixture and & (RSD) of retention time: $\leq 1 \%$ & Relative standart deviation (RSD): \\
nanoparticle form) & & $0.037 \%$ \\
\hline
\end{tabular}

\section{CONCLUSION}

A nanoparticle of Centella asiatica extract has formed. The three different formulation conditions, namely inlet temperatures of 140,150 , and $160^{\circ} \mathrm{C}$ in the spray drying process have improved the physical appearances, moisture content, particle size, shape, and morphology. They were getting better with an increase in the inlet temperature used. However, the chemical characteristics of the nanoparticles show the opposite result. The increase in inlet temperature worsens the active compound content of the nanoparticles, which is indicated by a decrease in the quercetin value. This condition indicates that the use of the stabilizer combination has succeeded in improving the physical characteristics of nanoparticles. However, the inlet temperature value for the spray drying process needs to be further optimized. 


\section{ACKNOWLEDGEMENT}

The authors are grateful to the LPPM (Research institutions and community service) Faculty of Pharmacy, the University of Surabaya, for this research study's grant numbered 012/SP-Lit/LPPM01/FF/III/2019 and support.

\section{REFERENCES}

Ayyad, O. (2011). Novel strategies for the synthesis of metal nanoparticles and nanostructures (Tesis). Barcelona-: Universidad de Barcelona. http://hdl.handle.net/10261/42462

Bansal, S., Bansal, M., \& Kumria, R. (2012). Nanocrystals: current strategies and trends. International Journal of Research in Pharmaceutical and Biomedical Sciences, 3(1), 406-419

Dewi, A. K., \& Satibi, L. (2015). Kajian pengaruh temperatur pengeringan semprot (spray dryer) terhadap waktu pengeringan dan rendemen bubuk santan kelapa (coconut milk powder). Konversi, 4(1), 25-31.

Dixit, A. K., Singh, R. P., \& Singh, S. (2012). Solid dispersion - a strategy for improving the solubility of poorly soluble drugs. International Journal of Research in Pharmaceutical and Biomedical Sciences, 3(2), 960-966.

Idris, F. N., \& Nadzir, M. M. (2021). Comparative studies on different extraction methods of Centella asiatica and extracts bioactive compounds effects on antimicrobial activities. Antibiotics, 10, 457. https://doi.org/10.3390/antibiotics10040457

Kembaren, R., Putriliniar, S., Maulana, N. N., Yulianto, K., Ikono, R., Rochman, N. T., \& Mardliyati, E. (2014). Extraction and characterization of nano pigment powder from teak (Tectona grandis Linn. F) leaves). Jurnal Kimia Kemasan, 36(1), 191-196. https://doi.org/10.24817/jkk.v36i1.1904

Kumar, M. H. V., \& Gupta, Y. K. (2003). Effect of Centella asiatica on cognition and oxidative stress in an intracerebroventricular streptozotocin model of Alzheimer's disease in rats. In Clinical and Experimental Pharmacology and Physiology, 30, 336-342. https://doi.org/10.1046/j.14401681.2003.03842.x

Kumar, S. (2014). Spray-dried nano-crystalline powders and in vitro dissolution performance. Doctoral Dissertations, 311. https://opencommons.uconn.edu/dissertations/311

Liu, J., Liu, T., Mu, G., \& Chen, J. (2020). Wavelet-based calibration model building of NIR spectroscopy for in-situ measurement of granule moisture content during fluidized bed drying. Chemical Engineering Science, 226. https://doi.org/10.1016/j.ces.2020.115867

Loftsson, T., Hreinsdóttir, D., \& Másson, M. (2005). Evaluation of cyclodextrin solubilization of drugs. International Journal of Pharmaceutics, 302, 18-28. https://doi.org/10.1016/j.ijpharm.2005.05.042

Mendes, G. P., Kluskens, L. D., Mota, M., Lanceros-Méndez, S., \& Hatton, T. A. (2021). Spherical and needle-shaped magnetic nanoparticles for friction and magnetic stimulated transformation of microorganisms. Nano-Structures and Nano-Objects, 26. https://doi.org/10.1016/j.nanoso.2021.100732

Nansy, E., Harwoko, Pramono, S., \& Nugroho, A. (2015). Total flavonoid content and in vivo hypotensive effect of chloroform insoluble fraction of Centella asiatica leaf extract. International Food Research Journal, 22 (5), 2119-2125. http://www.ifrj.upm.edu.my

Nielsen, P. S. (2010). Method of controlling a spray dryer apparatus by regulating an inlet air flow rate, and a spray dryer apparatus. United States: US Patent (No. US 2010/0005683 A1).

Pramono, S., \& Ajiastuti, D. (2004). Standardization of pegagan extract (Centella asiatica (L.) Urban) based on asiaticoside content using TLC-densitometric method. Majalah Farmasi Indonesia, 15(3), 118-123

Rachmawati, H., Safitri, D., Pradana, A. T., \& Adnyana, I. K. (2016). TPGS-stabilized curcumin nanoparticles exhibit superior effect on carrageenan-induced inflammation in wistar rat. Pharmaceutics, 8(3), 1-13. https://doi.org/10.3390/pharmaceutics8030024 
Shargel, L., \& Yu, A. B. C. (2016). Applied Biopharmaceutics \& Pharmacokinetics Seventh Edition. In Applied Biopharmaceutics \& Pharmacokinetics Seventh Edition: Introduction to Biopharmaceutics and Pharmacokinetics (pp. 1-25). McGraw-Hill Education.

Sukmasari, M., \& Fatimah, T. (2006). Analisis kadar saponin dalam daun kumis kucing dengan menggunakan metode TLC-scanner. Temu Teknis Nasional Tenaga Fungsional Pertanian.

Sulaiman, T. N. S. (2007). Teknologi \& Formulasi Sediaan Tablet. Pustaka Laboratorium Teknologi Farmasi, Fakultas Farmasi, Yogyakarta: Universitas Gadjah Mada.

United States Pharmaceutical Convention. (2020). USPNF2021: Validation of Compend Procedures $\langle 1225\rangle$ : Issue 1. Available from: https://online.uspnf.com/uspnf

Watson, M. A., Lea, J. M., \& Bett-Garber, K. L. (2017). Spray drying of pomegranate juice using maltodextrin/cyclodextrin blends as the wall material. Food Science and Nutrition, 5(3), 820826. https://doi.org/10.1002/fsn3.467

Winarto, W. P., \& Surbakti, M. (2003). Khasiat dan Manfaat Pegagan, Tanaman Penambah Daya Ingat. Jakarta: Agromedia Pustaka

Zambrano, M. V., Dutta, B., Mercer, D. G., MacLean, H. L., \& Touchie, M. F. (2019). Assessment of moisture content measurement methods of dried food products in small-scale operations in developing countries: A review. Trends in Food Science and Technology, 88, 484-496. https://doi.org/10.1016/j.tifs.2019.04.006 